\title{
Properties of basalt fiber sulfo-aluminate modified cement binders
}

\author{
Inessa Paulava $^{1 *}$ \\ ${ }^{1}$ Brest State Technical University, 224017, Moskovskaya 267, Brest, Belarus
}

\begin{abstract}
The present paper considers the influence of basalt fiber method of addicting in to self-stressing concrete, modified by sulfoaluminate type expansive additive, on main properties of concrete. The use of basalt fiber and expansive additive together allows to obtain a composite with optimal structure and high-quality properties. The combined application allows to achieve several effects such as filling effect, pozzolanic effect and dispersed reinforcement effect (due to chaotic fiber distribution in the concrete composite structure and needle-shaped crystal of ettringite micro reinforcement). Use of even small amount of basalt fiber due to disintegration on a great amount of monofilaments with a great specific surface leads to an increase in concrete composite tensile strength due to spatial dispersed reinforcement effect and changing fracture toughness There is also an effect of simultaneous expansion due to adding an expansive additive and strengthening achieved by binding effect of basalt fiber as a dispersion-reinforcing element. The maximum amount of basalt fiber in the research is limited by $4 \%$ to prevent full percolation effect, but at the same time to provide the formation of filament spatial skeleton in the concrete structure. In this study are considered the changes of properties of the concrete composite with different degrees of expansion and self-stressing (varied by energy-activity and amount of sulfo-aluminate expansive additive). In the article the most optimal basalt fiber addicting method in the concrete mix is proposed, preferences and influence degree of this method on strength properties are determined. The integral use of the modifying expansive agent makes it possible to predict an increase in impermeability due to chemical-mechanical reinforcement of the structure, which results in durability of this type of concrete. This predetermines a perspective range of their applications in various kinds of structures including those with high serviceability.
\end{abstract}

Keywords: Self-stressed concrete, basalt fibre, sulpho-aluminate type additive, ettringite, dispersed reinforcement

\section{Introduction}

Nowadays, concrete is known as one of the most widely used composite materials worldwide. Being high performance in different environmental conditions, just economic, components availability, as well as high compressive strength, are among parameters which

\footnotetext{
*Corresponding author: pavlinna@tut.by
} 
makes it acceptable as a construction material. On the other side, it has tensile and strain weakness that reinforcement or various fibers usage compensate for that [1,2]. Adding fibers to concrete mixture can significantly improve its engineering properties such as tensile strength, flexural strength, impact and fatigue strength, as well as ductility, toughness and post-cracking capacity [3-5]. In recent years, fiber reinforced concrete (FRC) had a wide spread usage in civil engineering including roads pavement, bridges, slabs, explosives storages and so on [6,7]. FRCCs (fiber reinforced cementitious composites) are kind of compounds with appropriate uniformity and cohesion, capable of creating a ductile concrete. FRCCs performance depends on various parameters such as materials or fibers type and properties. Presence of cementitious supplementary materials (e.g. metakaolin, silica fume, fly ash, slag) as well as shape, size, type, content, and fibers distribution affects technical and economic efficiency.

Wide spectrum of fibers with different physical, mechanical and chemical properties are used and proposed for cementitious matrix reinforcement [8]. Among accessible, applicable fibers in cementitious composites steel, polypropylene, glass, carbon and basalt fibers can be mentioned $[8,9]$. Basalt fiber had recently a considerable development in concrete and cementitious products [8] due to its ecological and technical advantages.

In a literature review it was found many studies on the effect of various fibers including: natural, artificial, hybrid (steel, carbon, polypropylene, glass) on concrete performance. First attempt on concrete dispersed reinforcement was done by Baston and Ramualdi by placing steel fibers in 1960, USA [10]. According to researchers' study results, four main factors are effective in strength and bearing capacity of fibrous cementitious composites; matrix quality, dimensions ratio, volume fraction, and bond strength of fibers [11]. Nevertheless, bond failure related to fiber-matrix transition zone is the initial reason leading to the failure of the whole structure [12]. Many strategies are suggested to improve the bond properties at fiber-matrix transition zone, such as: (a) densification of the cementitious matrix and ITZ; (b) use of deformed fibers; (c) treatment of fibers surface [13-15]. Many densification methods have been proposed which include reduction in water-cement ratio, curing conditions, heat curing, and replacement of pozzolanic materials [16].

\section{Basalt fiber}

Basalt fibers, which are considered modern fibers with industrial potentials and less harmful for environment, have become a suitable alternative in the composites industries. Considering their physical and mechanical properties, basalt fibers are considered serious rivals for industrial fibers such as carbon and glass. Considering its properties including: greener, lighter, and reduction of reinforcement bars corrosion, basalt fibers have good potential for development of application in other industries [17,18]. Basalt fiber is a mineral matter with no environmental hazards, plus non-toxic and decomposable [19]. Considering high silica content in basalt stone structure, fibers made from it have become a suitable alternative, compatible with cementitious matrix. The tendency to use mineral basalt fibers in basalt fiber reinforced polymer (BFRP) is increasing and there have been different researches about the BFRPs [17-23].

By evaluating basalt fiber reinforced concrete, Dias et al. [24] reported that adding basalt causes decreased compressive strength and increased flexural or tensile strength. The basalt fibers caused the increased bearing and ductility in geo-polymeric concrete beam and it was also observed that the presence of basalt fiber raised beam's opening displacement which demonstrates less sensitivity at crack presence. The conducted studies imply the good strength of basalt against alkaline attacks [25]. Adding more than 1\% basalt decreased the mortar workability. Presence of fibers decreased the autogenous shrinkage of cementitious mortars by $15-20 \%$. The results show that optimal volume of basalt fibers was between $0.5 \%$ and $0.8 \%$. 
Ayub et al. [26] performed a study on mechanical properties and microstructure of Basalt Fiber Reinforced Concrete (BFRC). The results showed that adding basalt causes decreased concrete workability. The mechanical performance of basalt fibers in BFRC was better than Polypropylene. Compared to control specimen, BFRCs showed higher flexural and tensile strength which intensifies by increased fiber length. After 28 days, the compressive, tensile and flexural strength of BFRC with fiber length of $12 \mathrm{~mm}$ increased $0.18 \%$ to $4.68 \%, 14.08 \%$ to $24.34 \%$ and $6.30 \%$ to $9.58 \%$ respectively.

But, long term durability of BFRC composites has been a major concern in limiting the widespread application of the material. OPC matrix BFRC demonstrates significant reductions in tensile strength and ductility as time develops, particularly in humid environments $[27,28]$. The degradation is normally associated with fiber corrosion by the high alkalinity within the matrix [29-31] and/or loss of fiber flexibility by the precipitation of $\mathrm{CH}$ within and around basalt fiber strands [28,29,32]. Therefore efforts have been directed towards the study of modified matrix formulations with markedly reduced alkalinity and/or propensity to precipitate calcium hydroxide.

Sulfo-aluminate (SA) modified binder, often considered as a potential low-carbon binder and as a shrinkage-compensating additive, demonstrates potential as an addition to improve the durability properties of BFRC composites. This can be attributed to the intrinsically different hydration process of SA-OPC blended cement, which is $\mathrm{CH}$ free and thus provides a less alkaline and less aggressive environment for embedded basalt fibers.

Variation in amount and type of used expansive additive make it possible to obtain selfstressing concretes with different level of linear expansive strains and self-stresses. Expansion mechanism is based on early ettringite formation (see fig. 1).

$$
3 \mathrm{CaO} \cdot \mathrm{Al}_{2} \mathrm{O}_{3}+\mathrm{CaSO}_{4} \cdot 2 \mathrm{H}_{2} \mathrm{O}+26 \mathrm{H}_{2} \mathrm{O} \rightarrow 3 \mathrm{CaO} \cdot \mathrm{Al}_{2} \mathrm{O}_{3} \cdot 3 \mathrm{CaSO}_{4} \cdot 32 \mathrm{H}_{2} \mathrm{O}
$$

Combined introduction of basalt fiber with expansive admixture leads to the advantageous stress-strain relationship due to chemical prestress and spatial reinforcement.

As can be seen from fig. 2, the addicting of basalt fiber does not lead to a sharp decline in linear expansion, which allows maintaining the required level of energy activity. At the same time, the binding of a hydrating system to a spatial framework will prevent partial decompaction and strength decreases inherent in energy-active mixes.
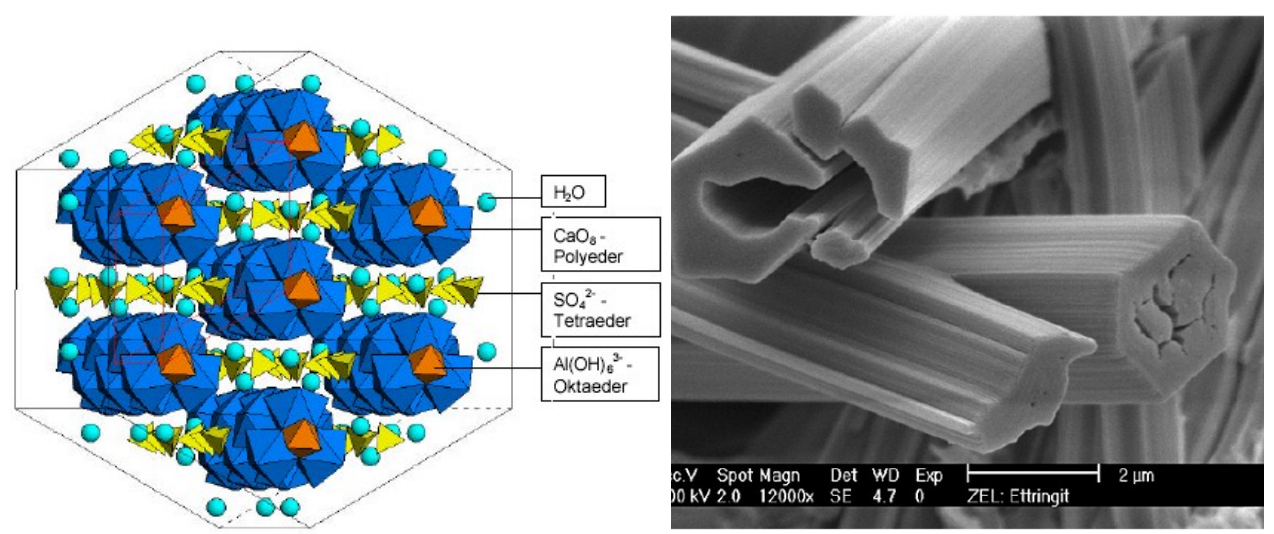

Fig. 1. Ettringite structural model (according to J.Neubauer (left) and crystal microphotography (right). 


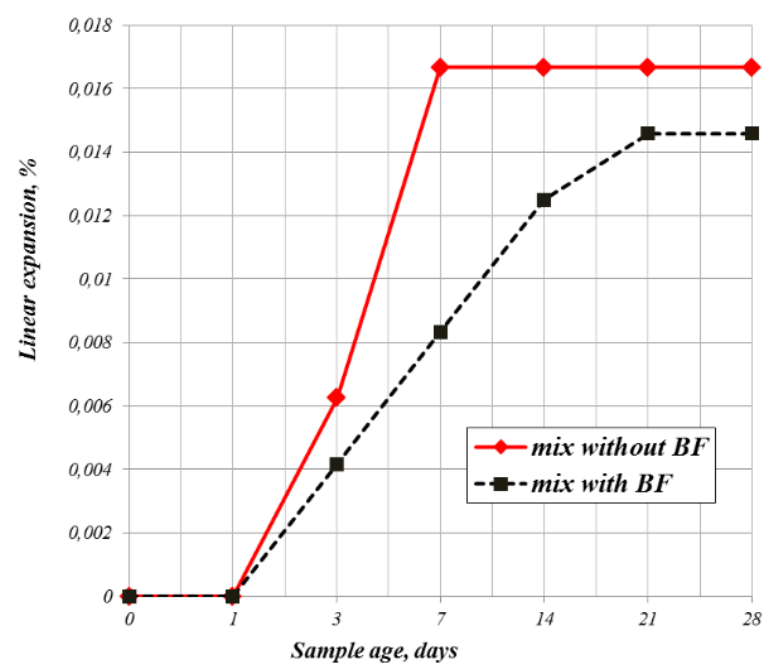

Fig. 2. Dependence of linear expansion development in time (BF - basalt fiber).

This paper compares the microstructure and mechanical properties of BFRC composites made with two different matrix formulations (OPC, and SA-OPC blend). Also, considered method of fiber addicting into the prepared mix.

\section{Materials and methods}

The type of cement used in all mixtures was CEM I42.5 according to EN 197-1 and its chemical compositions and physical properties presented in Table 1. An expansive sulfoaluminate (SA) additive was used in this study with the chemical composition seen in Table 1. In order to observe the effect of SA additive on mechanical properties and microstructure of composites, it was used as a replacement of cement materials in different value of $10 \%$ by weight.

Table 1. Chemical compositions of cement and sulfo-aluminate additive.

\begin{tabular}{|c|c|c|c|c|c|c|c|c|c|c|}
\hline & \multicolumn{7}{|c|}{ Chemical compositions (\% by weight) } & \multicolumn{2}{c|}{$\begin{array}{c}\text { Physical } \\
\text { properties }\end{array}$} \\
\cline { 2 - 11 } & $\mathrm{CaO}$ & $\mathrm{SiO}_{2}$ & $\mathrm{Al}_{2} \mathrm{O}_{3}$ & $\mathrm{Fe}_{2} \mathrm{O}_{3}$ & $\mathrm{MgO}$ & $\mathrm{K}_{2} \mathrm{O}$ & $\mathrm{Na}_{2} \mathrm{O}$ & $\mathrm{SO}_{3}$ & $\begin{array}{c}\text { Densit } \\
\mathrm{y} \\
\left(\mathrm{g} / \mathrm{cm}^{3}\right)\end{array}$ & $\begin{array}{c}\text { Blain } \\
\text { surface } \\
\left(\mathrm{m}^{2} / \mathrm{kg}\right)\end{array}$ \\
\hline $\begin{array}{c}\text { Ordinary } \\
\text { Portland } \\
\text { cement } \\
\text { (OPC) }\end{array}$ & 62,22 & 19,73 & 5,45 & 2,65 & 2,09 & 1,05 & 0,17 & 2,99 & 3,10 & 320 \\
\hline $\begin{array}{c}\text { Sulfo- } \\
\text { aluminate } \\
\text { addictive } \\
\text { (SA) }\end{array}$ & 34,31 & 8,12 & 26,55 & 0,50 & 0,54 & 0,09 & 0,06 & 30,69 & 2,92 & 827 \\
\hline
\end{tabular}

Basalt Fiber with following properties (see table 2) was used throughout the study (at contents $0 \%, 1 \%$ and $1.5 \%$ by volume).

In these studies were considered two schemes for loading materials during the preparation of fiber-concrete mix (see Ошибка! Источник ссылки не найден.). 
Table 2. Technical characteristics of the used basalt fiber.

\begin{tabular}{|l|c|}
\hline \multicolumn{1}{|c|}{ Name of the indicator } & Value \\
\hline Basalt fiber length, $\mathrm{mm}$ & 24,5 \\
\hline $\begin{array}{l}\text { The diameter of the individual monofilament, } \\
\mu \mathrm{M}\end{array}$ & 16 \\
\hline Modulus of Elasticity, $\mathrm{MPa}$ & $93200-116000$ \\
\hline Rupture strength, $\mathrm{MPa}$ & $1500-2000$ \\
\hline Density, $\mathrm{g} / \mathrm{cm}^{3}$ & 2,7 \\
\hline
\end{tabular}

Table 3. Technical characteristics of the used basalt fiber.

\begin{tabular}{|c|l|l|}
\hline \multirow{2}{*}{$\begin{array}{c}\text { № of } \\
\text { stage }\end{array}$} & \multicolumn{1}{|c|}{ Scheme 1 } & \multicolumn{1}{c|}{ Scheme 2 } \\
\cline { 2 - 3 } & \multicolumn{1}{|c|}{ Mix components } & \multicolumn{1}{c|}{ Mix components } \\
\hline 1 & SA-OPC+Sand & SA-OPC +Water+ Plasticizer $(0,8 \%)$ \\
\hline 2 & Basalt fiber (4\%) & Basalt fiber (4\%) \\
\hline 3 & Water+Plasticizer $(0,8 \%)$ & Sand \\
\hline
\end{tabular}

\section{Results and discussion}

\subsection{DTA}

A prominent composite triple endotherm at $100-180{ }^{\circ} \mathrm{C}$ is generally associated with the presence of (in the order of dehydration temperature) weakly-bound pore water, $\mathrm{C}-\mathrm{S}-\mathrm{H}$ gel and/or ettringite. Dehydroxylation of $\mathrm{CH}$ occurs between 500 and $550{ }^{\circ} \mathrm{C}$. The low temperature peak for SA additive is significantly larger than that for OPC and the most prominent sub-peak is shifted towards higher temperature, suggesting a relative preponderance of ettringite over C-S-H (Fig. 3). The absence of the $\mathrm{CH}$ endotherm is clear in SA-OPC compound. Peaks between 600 and $780{ }^{\circ} \mathrm{C}$ are indicative of the existence of $\mathrm{CaCO}_{3}$, but very little seems to be apparent in either material.

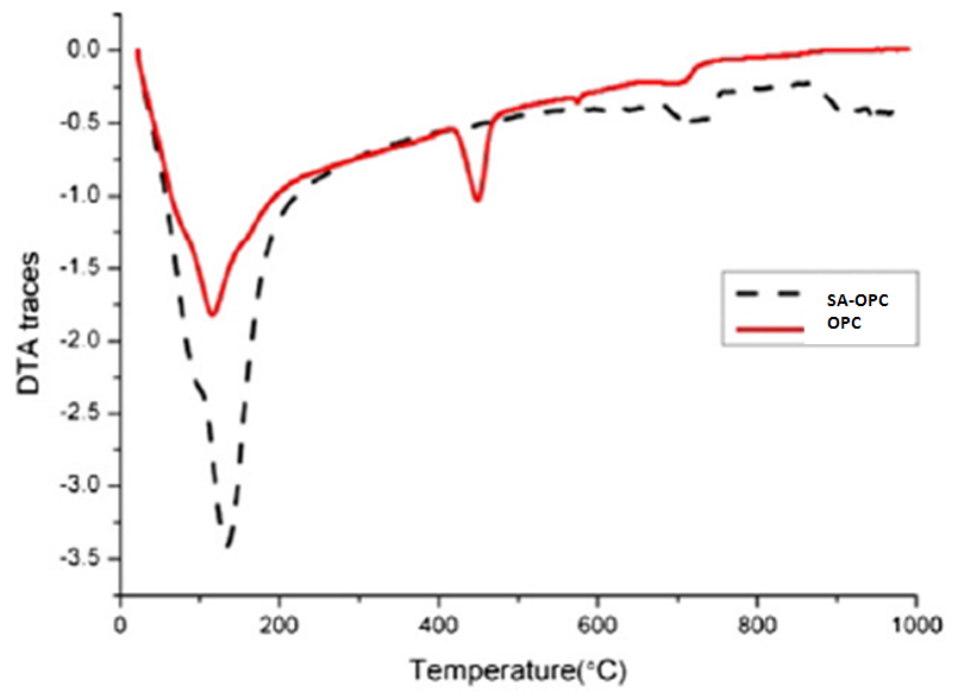

Fig. 3. DTA thermo grams of OPC and SA-OPC matrices. 


\subsection{X-ray diffraction}

XRD results (Fig. 4) confirm that SA additive is free of $\mathrm{CH}$ and relatively large amounts of ettringite can be observed, confirming the DTA results above. A broad band between $2 \theta=$ 33 and $34^{\circ}$ reveals significant remnants of unhydrated $\mathrm{C}_{2} \mathrm{~S}$ in SA-modified cement systems; this may be attributed to rapid water consumption during the hydration of calcium sulfoaluminate within the first 1-2 days, which leaves insufficient water for the hydration of belite at later ages.

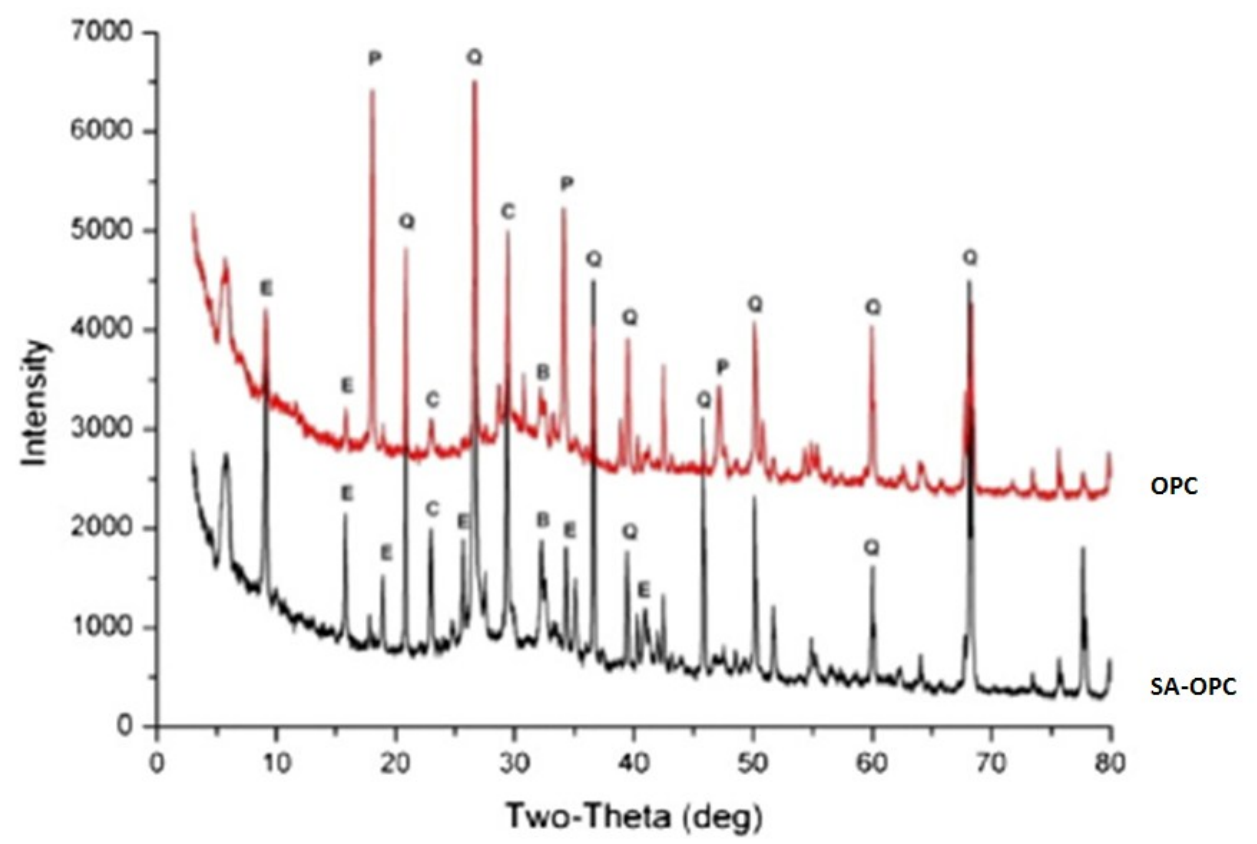

Fig. 4. X-ray diffraction patterns of samples (E-ettringite, $\mathrm{P}-\mathrm{Ca}(\mathrm{OH})_{2}$, Q-quartz, $\mathrm{C}-\mathrm{CaCO}_{3}$, B-belite).

\subsection{SEM}

Scanning electron microscope (SEM) is one of the most effective and helpful instruments to understand the morphology of cementitious composites structure. In order to recognize the bond quality between fibers and cementitious matrix, a projective evaluation of cement paste microstructure was made using microscopic images. Composites with SA and basalt fibers were investigated and their SEM images are shown in Fig. 5. Fig. 5 (a) presents the composites on ordinary PC. It indicates that crystallized flake-shaped structures have a considerable volume including great amount of Portlandite and can be the main reason of relatively low strength of these specimens. It can be concluded that the interfilamentary phases in SA-OPC are mainly $\mathrm{C}-\mathrm{A}-\mathrm{S}-\mathrm{H}$ gel finely intermixed with $\mathrm{AFt}$ phases at various levels (Fig. 5 (b)). The observed microstructure of OPC (Fig. 5 (a)) indicated that the matrix space was significantly filled with hydration products, mainly dominated by $\mathrm{Ca}$ and $\mathrm{Si}$ according to the elemental mappings. Analysis reveals dominance of $\mathrm{CaO}$ (53.0 wt.\%) and $\mathrm{SiO}_{2}(42.2 \mathrm{wt} . \%)$ at the interfilamentary space. In modified by SA cement paste $\mathrm{Al}$ and $\mathrm{S}$ could be observed between fibers, thus eliminating the presence of ettringite and/or AFm in this zone (Fig 5 (c)). 
a)

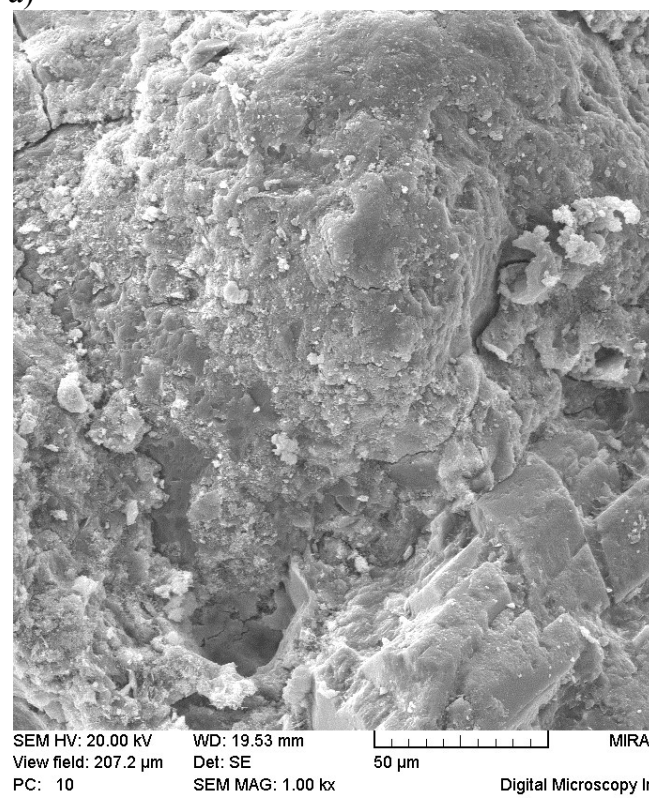

b)

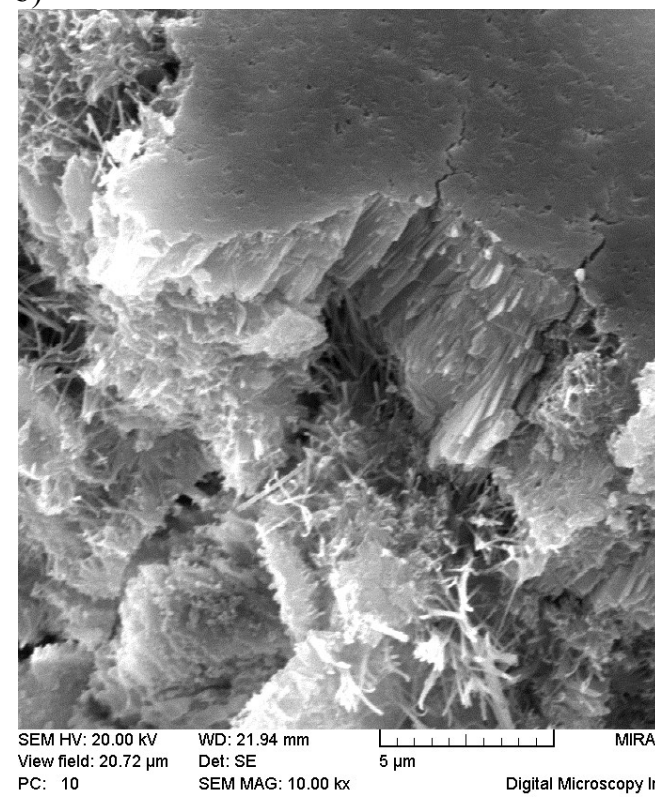

c)

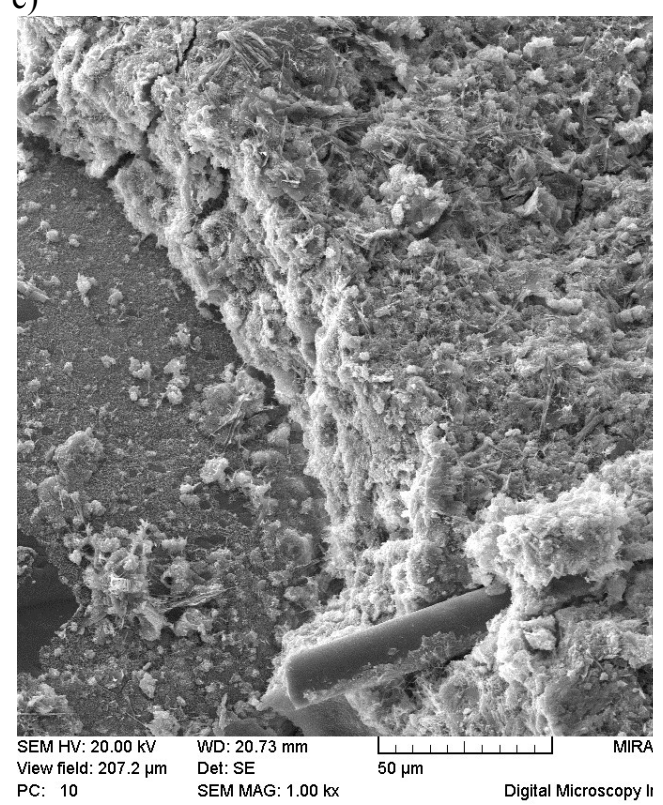

Fig. 5. Scanning electron microscope images of fiber reinforced specimens a - OPC; b - SA-OPC; $\mathrm{c}-\mathrm{SA}-\mathrm{OPC}+$ basalt fiber.

\subsection{Method of fiber addicting}

One of the purposes of this study was to determine the most optimal of the methods of basalt fiber addicting into a concrete mix. 
There were proposed two schemes of the basalt fiber addicting into the concrete mix:

- scheme 1 - the introduction of basalt fiber in a dry mix of cement and sand, obtaining a homogeneous mixture of dry components and their subsequent mixing with water and a plasticizing additive;

- scheme 2 - the introduction of basalt fiber in prepared suspension consisting of cement, water and plasticizer, obtaining a homogeneous mixture and the subsequent introduction of sand with the joint mixing of all the components of the fiber-concrete mix.

The composition without basalt fiber was taken as the control.

Tensile strength was chosen as control.

Tests of control samples were made at the age of 2, 7 and 28 days. The results are presented in Fig. 6.

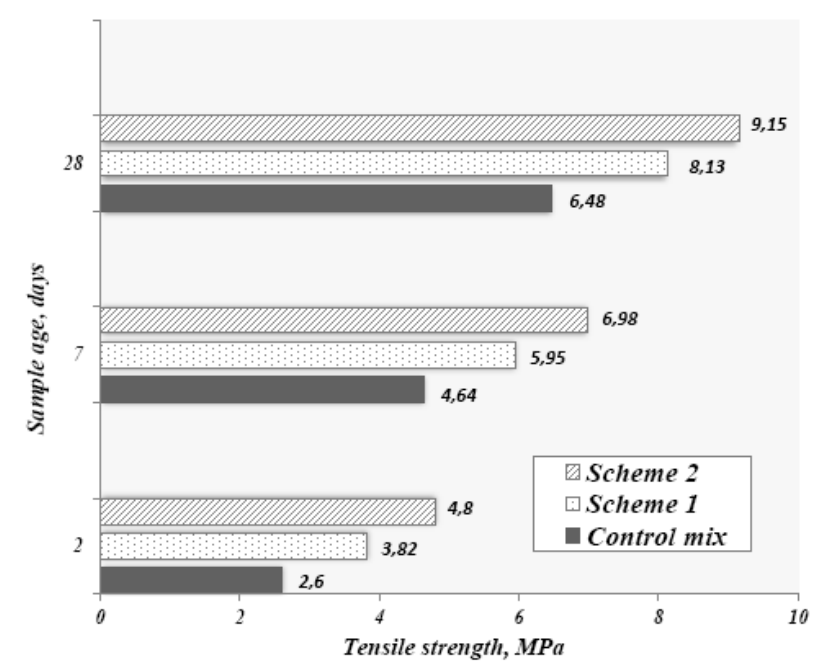

Fig.6. Sample tensile strength.

\section{Conclusions}

1. The combined use of basalt fiber and an expansive sulfo-aluminate additive in the hydrating cement system allows to achieve the effect of expansion (or shrinkage compensating) without decompression and decrease in strength, which is usually is shown in energy-active compounds. At the same time, the addicting of basalt fiber slightly reduces the strain of free expansion, which allows that the energy potential of active expansive binders to be fully realized.

2. Dispersed basalt fiber reinforcement of cement systems leads to the creation of a spatial framework, due to the free and chaotic distribution of elementary fibers in the cementitious matrix. Intrinsically different hydration process of SA-OPC blended cement, which provides a less alkaline and less aggressive environment for embedded basalt fibers improves microstructure and leads to durability increase.

3. BFRC on SA-OPC blended binders have an average tensile strength of $25 \%$ higher than the strength of control samples on OPC without fiber. The maximum effect in increasing strength was shown at an early age (the increase in strength was from $32 \%$ to $45 \%)$.

4. Optimal way of basalt fiber addicting into the concrete mix in suspension achieved the uniform distribution of fibers in the cement matrix. 


\section{References}

1. ACI T. Uygunog `lu, Mater. Struct. 41,1441 (2008)

2. E. Güneyisi, M. Gesog lu, A.O. Akoi, K. Mermerdas, Compos. Part B-Eng., 56, 83 (2014)

3. S. Iqbal, A. Ali, K. Holschemacher, T.A. Bier, Constr. Build. Mater., 98, 325 (2015)

4. K. Hannawi, H. Bian, W. Prince-Agbodjan, B. Raghavan, Compos. Part B-Eng., 86, 214 (2016)

5. M.L. Santarelli, F. Sbardella, M. Zuena, J. Tirillò, F. Sarasini, Mater. Des. 63, 398 (2014)

6. J. Kim, D.J. Kim, S.H. Park, G. Zi, Compos. Struct., 122, 198 (2015)

7. C. Lin, O. Kayali, E.V. Morozov, D.J. Sharp, Cem. Concr. Compos., 51, 27 (2014)

8. P. Zhang, Q.F. Li, Compos. Part B-Eng., 45, 1587 (2013)

9. X. Wang, Z. Wang, Z. Wu, F. Cheng, Constr. Build. Mater., 73, 781 (2014)

10. S.T. Buljan, A.E. Pasto, H.J. Kim, Advanced Structural Ceramics: Properties, Reliability and Applications (1986)

11. K. Wille, A.E. Naaman, ACI Mater. J., 109, 4 (2012).

12. S.F. Lee, S. Jacobsen, Mater. Struct., 44, 1451 (2011)

13. T. Abu-Lebdeh, S. Hamoush, W. Heard, B. Zornig, Constr. Build. Mater., 25, 39(2011)

14. Z. Wu, C. Shi, W. He, L. Wu, Constr. Build. Mater., 103, 8 (2016)

15. V.C. Li, H.C. Wu, Y.W. Chan, J. Am. Ceram. Soc., 79, 700 (1996)

16. X.H. Wang, S. Jacobsen, S.F. Lee, J.Y. He, Z.L. Zhang, Mater. Struct., 43, 125 (2010)

17. N. Morova, Constr. Build. Mater., 47, 175 (2013)

18. V.I. Fiore, G. Di Bella, A. Valenza, Mater. Des., 32, 2091 (2011)

19. Y. Zhang, C. Yu, P.K. Chu, F. Lv, C. Zhang, J. Ji, H. Wang, Mater. Chem. Phys., 133, 845 (2012)

20. T. Bhat, V. Chevali, X. Liu, S. Feih, A. Mouritz, Compos. Part A, 71, 107 (2015)

21. R. Li, Y. Gu, Z. Yang, M. Li, S. Wang, Z. Zhang, J. Nucl. Mater., 466, 100 (2015)

22. V. Manikandan, J.W. Jappes, S.S. Kumar, P. Amuthakkannan, Compos. Part B-Eng., 43, 812 (2014)

23. D. Yeboah, S. Taylor, D. McPolin, R. Gilfillan, Constr. Build. Mater., 38, 962 (2013)

24. D.P. Dias, C. Thaumaturgo, Cem. Concr. Compos., 27, 49 (2005)

25. B.E. Ramachandran, V. Velpari, N. Balasubramanian, J. Mater. Sci., 16, 3393 (1981)

26. T. Ayub, N. Shafiq, S.U. Khan, J. Mater. Civ. Eng., 28, (2015).

27. A. Bentur, S. Mindess, Fibre Reinforced Cementitious Composites, Elsevier Applied Science, London (1990)

28. A.J. Majumdar, V. Laws, Glass Fibre Reinforced Cement, BSP Professional Books, Oxford (1991)

29. A. Bentur, Proceedings of Durability of Glass Fibre Reinforced Concrete Symposium (1985)

30. P. Purnell, et al., Compos. A: Appl. Sci. Manuf., 30, 1073 (1999)

31. J. Orlowsky, M. Raupach, Mater. Struct., 39, 635 (2006)

32. R.C. Devekey, A.J. Majumdar, J. Mater. Sci., 5, 183 (1970) 